\title{
LA CRISIS DE MARZO DE 1969 EN GUINEA ECUATORIAL
}

\author{
Dr. D. Javier Martínez Alcázar \\ Murcia. España
}

La llamada y no siempre bien estudiada crisis de Marzo de 1969 entre los Gobiernos de España y de la República de Guinea Ecuatorial, o mejor, entre aquél y Francisco Macias Nguema, comenzó a vislumbrarse en las dos últimas semanas de Diciembre, cuando determinados grupos de jóvenes realizaron acciones tumultuosas en algunas ciudades de Rio Muni especialmente en Ebebigin y Niefang ${ }^{1}$. En este ambiente se produjo el más grave y primero de una serie de incidentes, como preludio de la creciente tensión entre los gobiernos de España y de Guinea Ecuatorial, que se hubieran podido evitar si España hubiese hecho valer los derechos que le conferían los acuerdos de cooperación firmados con Guinea Ecuatorial. Entre los muchos protocolos firmados por España el día doce de Octubre de 1968, día de la independencia de Guinea Ecuatorial, había un convenio para el período transitorio que finalizaría con la firma de un acuerdo de Cooperación. "El representante plenipotenciario del Gobierno español, Excmo. Sr. D. Manuel Fraga Iribarne, ministro encargado de Asuntos Exteriores y el Presidente de la República de Guinea Ecuatorial, Excmo. Sr. Don Francisco Macias Nguema, teniendo presentes los superiores intereses del Estado y en uso de los poderes que les confiere el articulo 56 de la Constitución ${ }^{2}$, de acuerdo con la declaración del Gobierno español en la Conferencia Constitucional de Madrid de ayudar al nuevo Estado guineano para consolidar la independencia, la paz y la prosperidad. Deseosos de evitar que el acceso a la independencia pueda provocar dificultades en la continuidad de los servicios públicos. Dispuestos a asegurar la estabilidad de las relaciones entre ambos paises en tanto que no se llegue al establecimiento de unos Acuerdos de asistencia mutua, que han de ser negociados para la regulación de la vida económica y social de la nación guineana. Convencidos de la necesidad de acordar disposiciones concretas para asegurar las buenas relaciones: adoptan el presente Convenio que se incorpora al Acta de la independencia firmada en el dia de hoy y en el cual acuerdan lo siguiente. III.- El estatuto jurídico de los funcionarios y demás personal español al servicio del

1 Ebebiyin ciudad situada en el extremo nordeste de Río Muni y punto de enlace entre Bata y la zona nordeste. Fue la ruta utilizada por aquellos guineanos que se vieron obligados a abandonar Guinea en época de Macias. Niefang es la ciudad límite entre el mundo fang y las tribus playeras de la Guinea continental. Situada a 50 kilómetros de Bata, es un importante nudo de comunicaciones.

2 La primera Constitución de Guinea Ecuatorial fue la de 1968 que habia sido preparada en las dos sesiones de la Conferencia Constitucional reunida en Madrid en 1968. 
Gobierno de Guinea Ecuatorial será garantizado conjuntamente por los gobiernos de ambos países, ajustándose a las siguientes bases:

a) la prestación del servicio se regirá por las disposiciones generales vigentes en Guinea Ecuatorial.

b) el Estatuto de los funcionarios y del restante personal será el establecido actualmente.

c) los derechos económicos computados con cargo al Presupuesto de Ayuda a que se refiere la cláusula XI, serán asegurados por el Gobierno español, que ejercerá la potestad disciplinaria, bien por iniciativa propia, mediante los medios previstos en la legislación, bien como consecuencia de la solicitud del Gobierno de Guinea.

d) ambos paises garantizarán, de acuerdo con la legislación que les sea aplicable, el régimen de destino salvo que, previo acuerdo de ambos gobiernos, se deban cubrir otros servicios,

e) los agentes de seguridad, policia y orden piblico españoles que permanezcan al servicio del Gobierno guineano, estarán a disposición de las autoridades de Guinea, en la forma que se determine para el acatamiento del respeto la legalidad y a las personas y para hacer posible la normal y pacifica convivencia ciudadana.

f) los funcionarios españoles del orden judicial continuarán desempeñando sus funciones y administrarán justicia en nombre del Presidente de la República de Guinea Ecuatorial; estarán sometidos su propio estatuto orgánico y se les garantizará su independencia e inamovilidad.

g) el Gobierno español, de acuerdo con los programas del Gobierno de Guinea Ecuatorial, facilitará en sus centros de formación técnica y administrativa, la capacitación de los guineanos para su progresiva incorporación a las tareas técnicas y administrativas de la nación.

XIII.- Ambos gobiernos establecerán, de muiuo acuerdo, el Estatuto de las Fuerzas armadas españolas, mientras permanezcan en el territorio de Guinea Ecuatorial."

Precisamente, y en virtud el Convenio existente, Don Martín Zato, que ostentaba el cargo de fiscal general del tribunal Supremo de Guinea Ecuatorial de Santa Isabel ${ }^{3}$, con todas las prerrogativas y obligaciones que por su cargo debía tener en virtud de los Acuerdos transitorios, el 26 de Diciembre de 1968, visitó al Ministro del Interior de Guinea Ecuatorial para manifestarle (ésta era verdaderamente su obligación), que la detención más allá de las setenta y dos horas de cualquier ciudadano, sin dar cuenta de ello a la autoridad judicial contravenía lo establecido en la ley. El Ministro del Interior, pensó, no sin cierta razón, que esto era una maniobra en favor de Bonifacio Ondó, puesto que si bien era verdad que la deten-

3 Santa Isabel, hoy Malabo. Capital de Guinea Ecuatorial. Ciudad situada al norte de la isla de Fernando Poo. Fue llamada por los ingleses Port Clarence y posteriormente, Santa Isabel en honor de la reina de España.

4 Bonifacio Ondó Edú. Presidente del MUNGE y candidato apoyado por Carrero Blanco en las elecciones a la presidencia de Guinea Ecuatorial, que perdió. Por ello, después de las elecciones y temiendo por su vida se refugió en Gabón. El Gobiemo de Gabón, después de recibir seguridades del Gobierno de Guinea de que no 
ción de Ondó Edú era ilegal, también era cierto que por aquellas fechas las cárceles de Guinea Ecuatorial estaban llenas de presos menores sin que nadie hiciera nada por ellos. Las flamantes autoridades españolas que ejercian sus cargos en Guinea Ecuatorial empezaban pronto a hacer dejación de su autoridad.

El Ministro del Interior informó inmediatamente a Macias de la visita que le había hecho el fiscal General y el Gobierno español consciente de que debía presionar un poco más en este asunto, ordenó a su embajador en Santa Isabel, Don Juan Durán-Lóriga ${ }^{5}$ que visitase al presidente Macias para hacerle ver que España nada tenía que ver con la gestión del fiscal Zato por cuanto éste solo estaba cumpliendo con su deber. A Macias no se le pudo escapar que, pese al lenguaje diplomático empleado por Durán-Lóriga, el Gobierno español estaba haciendo esfuerzos para intentar sacar de la cárcel a Ondó Udú. Hacía solo dos meses desde la independencia y este problema era, en verdad, muy serio. Pero Macias se percató del interés de España demostraba por Bonifacio Ondó, y como estaba en su retorcida menta su voluntad de empezar a ofender a España cuanto antes, comunicó al embajador su decisión de expulsar al fiscal Zato. Era cierto que ni el Convenio transitorio ni la ley permitían a Macias tomar esta medida, pero se debió sentir muy presionado por el embajador de España, y porque todavía no había tomado ninguna determinación sobre su enemigo politico Ondó Edú. El embajador Durán-Lóriga protestó enérgicamente y manifestó a Macias que esta decisión podía poner en peligro la cooperación y la buena amistad hispano-guineana con consecuencias gravisimas para su país. La práctica de la amenaza velada fue muy utilizada por Durán-Lóriga durante su corta y desastrosa gestión al frente de los intereses de España en Guinea Ecuatorial. Intentó convertirse, sin éxito, en un gobernador en la sombra.

Pienso que fue la gestión del embajador Durán-Lórica ante Macias lo que convirtió en un problema político grave un hecho que se podía haber resulto con un poco de mano izquierda y alguna gestión burocrática. El embajador de España logró que Macias retirase la orden de expulsión del fiscal Zato, pero éste debia abandonar Guinea a petición propia. Lo cual, evidentemente, era lo mismo pues en cualquier caso el fiscal general estaba haciendo dejación de su autoridad y el Gobierno español aceptaba esta política de hechos consumados.

En una Nota Informativa Circular del Ministerio de Asuntos Exteriores de siete de Enero de 1969, se hacía referencia a la crisis del caso Zato y el Ministerio se preguntaba: "no declarar una crisis en las relaciones entre España y Guinea a los tres meses de declarada la independencia. Pero debe también sopesarse sino ha llegado la hora de afioniar resueltamente el riesgo de dicha crisis si la resolución de la misma clarifica la situación entre ambos paises". La Nota Informativa continuaba haciendo una valoración sobre si con-

le ocurriria nada a Bonifacio Ondo, le situó en la frontera de Guinea. En Enero de 1969 fue acusado de estar involucrado en una tentativa de golpe de Estado y por ello fue encarcelado. En Abril fue ejecutado después de
haber sido sometido a torturas.

5 Juan Durán-Lóriga Rodrigañez. Habia ocupado diversos puestos antes de ser nombrado Director General de Africa. Fue el primer embajador de España en la República de Guinea Ecuatorial. Expulsado durante la 1lamada crisis de las banderas. En 1969 fue nombrado embajador de España en Jordania. 
venía o no, en un futuro, hacer uso de las prerrogativas que el Convenio Transitorio concedía al Gobierno español. "Los problemas económicos y la total dependencia del Gobierno guineano, proponcionan instrumentos suficientes para ejercer la presión que se considerase necesaria. La justa irritación española y la imprescindible acción que se manifiesta debe ser planeada y ejecutada de manera que no desencadenase contradicciones que produzcan una escalada de efectos para los intereses que se dice querer defender: Debe escogerse una acción concreta, claramente delimitada y con suficientes consecuencias negativas para el Gobierno de Guinea, de manera a que por si misma tenga el suficiente valor retorsivo (el subrayado es mio). Lo que hay que considerar es que dicha acción no puede ser presentada o interpretada como la consagración de esa supuesta tendencia de la administración, sino del Gobierno español en favor del abandono gradual de Guinea Ecuatorial.

Habían pasado solo tres meses desde la independencia y se estaba planteando por parte de un alto funcionario español la posibilidad de abandonar Guinea Ecuatorial. Llegados a este punto conviene aclarar que una Nota Circular expresa la opinión realizada en voz alta por un funcionario, pero en absoluto supone la postura oficial del Gobierno español. Por tanto, era el señor Fernando Morán, a la sazón subdirector general de África Subsahariana, del Ministerio de Asuntos Exteriores, el autor de esta reflexión, quien, por medio de esta Nota, informaba al Director General de Áfricá. Aclarado el hecho de que una Nota informativa no refleja la posición política de un Gobierno sobre un asunto concreto, no deja de ser preocupante que la Nota de referencia se preguntase ya en Enero de 1969 sobre la posibilidad de ir abandonando Guinea Ecuatorial a su suerte.

Pero continuemos con el análisis de la Nota Informativa, que no tiene desperdicio. "El principio esencial de la política española en Guinea es el respeto a la autoridad vigente, la no injerencia en sus asuntos internos y el trato con su Gobierno tal y como está consituido -de tendencia presidencialista- mostrándose con él generoso, pero a la vez marcando los limites de lo que es posible tolerar. Una politica clarificadora tanto de los que España ofrece como de lo que está dispuesta a admitir es urgente y, previsiblemente, está todavía en plazo, es decir, que aún es tiempo de encaminar satisfactoriamente la situación guineana en la cual los incidentes reseñados pueden ser un capitulo negativo corregible al que sigan otros muy satisfactorios para ambas partes".

Habia, pues, buena voluntad por parte del Gobierno español para con el Gobierno guineano, pero ésta era ambivalente, como voy a tratar de demostrar. Por una parte el Gobierno español quería, parece ser, permanecer en Guinea. Pero, por otra parte, el Gobierno guineano no hacía ningủn gesto de buenas intenciones hacia España. La crisis, en realidad, comenzó a tomar un cariz muy preocupante cuando Macias comenzó una campaña de discursos demagógicos iniciando una situación de instabilidad que produjo una primera víctima (y la única, es cierto), en un joven español que intentaba huir en barca de Guinea. A finales de Diciembre y con motivo de la primera gira oficial del Presidente Macias por el Continente

6 Fernando Morán. Diplomático español que con el primer Gobierno socialista se convirtió en Ministro de Asuntos Exteriores. 
provocó una serie de amenazas y ultrajes contra los intereses españoles. A partir de Febrero estas amenazas se transformaron en violencias físicas y así, fueron maltratados Don Manuel Barral, Don Jesús Uriarte y Don Justo Garita, y fueron expulsados varios médicos y otros funcionarios españoles cuyas cuentas habían sido bloqueadas precisamente por el gobierno guineano.

El encargado de iniciar la tensión entre España y Guinea Ecuatorial iba a ser el propio presidente Macias con sus discursos contra España. Así, el 17 de Enero decía en Santa Isabel. "Yo y mi pueblo nos entregariamos a la lucha. Sabed que son pocos y aunque tengan armas, nosotros con machetes hariamos la guerra... ¿Cómo se liberó Kenia? Porque el Mau-Mau se enfrentó a los ingleses. Nosotıs también luchariamos con machetes, porque mi pueblo me respalda... y si a mi me matan, mi sucesor se encargaria de hacer estallar la guerra y entonces los españoles saldrian mal de Guinea Ecuatorial. ... La lucha de la independencia africana no se ha comprendido. El hombre que hizo posible la independencia de Africa fue Hitler. Ese es el hombre que nos ha dado la libertad.

En febrero y ya en la zona continental de Guinea, el Presidente Macias hizo un durísimo discurso en Lea: "Ahora la única lucha que queda es para expulsar a la guardia civil. Luchamos para expulsarlos. El nuevo Presidente de Guinea Ecuatorial no puede sentirse satisfecho sino se expulsa a la guardia Civil que asesinó a Acacio Mañé ya otros tantos africanos.... Precisamente hoy hemos puesto un telegrama a Franco para evacuar esas fuerzas que solo vienen a matar. La juventud, os pido un favor, los colonialistas se han rendido, no pegarles más. Hemos recuperado nuestra casa (se refiere a la residencia del Cónsul general de España en Bata), expulsando al embajador y desalojando al cónsul de España. Los madereros son nuestros primeros enemigos. Si dentro de poco no se someten a mi Gobierno nacionalizaremos sus bienes".

El sábado 16 de febrero se dirigió en los siguientes términos a la población de Bimbiles: También quiero referirme al problema de la madera que creo que os preocupa. Tengo muchas quejas sobre las empresas madereras y tomará medidas muy serias al respecto. El nuevo Gobierno va a exigir a los capitalistas medereros que no han hecho nada por Guinea Ecuatorial, nada más que llevarse la riqueza, ¡Mirad como en Rio Muni, un pueblo con much riqueza, esos empresarios no han hecho nada!. Los tinicos que han hecho han sido los pequeños comerciantes, porque en cada sitio han levantado su pequeña casita, han abierto sus negocios. En cambio, los grandes capitales madereros no han hecho nada por el pueblo de Guinea. Así pues, el nuevo Gobierno va a conocer de la situación de esas empresas, aunque de nuestros programas no quiero hablar aqui. Pero que les conste a los madereros que ellos van a ser responsables de la construcción de la carretera de Bata a Niefang, porque sus vehiculos son los que esiropean las carreteras $y$, por consiguiente, les

7 Acacio Mañé. Fang de origen camerunés que se trasladó a Bata para explotar una plantación. Perteneció desde sus comienzos a la cruzada de liberación nacional y más tarde al movimiento nacional de liberación de Guinea Ecuatorial. Con motivo del ingreso de España en NNUU, Mañé dirigió a la ONU un memorándum en contra de España. Murió en 1958 en circunstancias extrañas, aunque algunos autores como Liniger-Goumaz, han inculpado a la guardia civil en su asesinato. Esto no está, en absoluto, demostrado. 
vamos a exigir un impuesto muy severo para que se conserven las carreteras y puedan llevarse esa madera que, de momento, no está controlada. El nuevo Gobierno ahora no puede hacer milagros. estamos viendo como se llevan la madera y sabemos perfectamente que no está controlada. No quisiera emplear la violencia, pero quiero advertir a las empresas madereras desde el balcón de Bimbiles y que los periódicos difundan, que no se metan en politica, porque aún a estas alturas siguen haciéndolo. Como persistan en su actitud el nuevo Gobierno nacionalizará sus bienes y no pasará nada.

El Viernes 28 de Febrero se encontraba en Bicui-Esacora y dijo: "estamos en lucha contra el imperialismo español. La lucha que tenemos estos dias es para expulsar a la Guardia Civil que asesinó a Acació Mañé. ${ }^{8}$ Por ello la Guardia Civil estacionada en Guinea Ecuatorial quedará incomunicada. Los principales promotores son el embajador de España y el cónsul que también serán expulsados del pais por incapacidad diplomática. No os preocupéis yo puedo sacar a la Guardia Civil que asesinó a Acacio Mañé, y a otros hermanos, la mayoria mutilados en sus cuerpos."

Y en Bindung: "El Gobierno de Francisco Macias no se sentirá independiente sino es evacuada inmediatamente la fuerza que asesinó a Acacio Mañé. Cuando yo hable, hablo a los asesinos que son la Guardia Civil que han estado malando a la población de Guinea Ecuatorial, lo sabéis todos. No puedo yo sentirme como Presidente de Guinea Ecuatorial en tanto no salga la Guardia Civil que asesinó a tantos guineanos. El embajador será tumbado para que vengan otros representantes de España a Guinea Ecuatorial. Estos guardias civiles son los que engendran la violencia del pais. También son enemigos nuestros los madereros y si de un momento a otro no se avengan a establecer negociaciones con el nuevo Gobierno, nacionalizaré todas las empresas madereras.

Pese al giro que Macias estaba dando a sus relaciones con España, Franco le envió una carta muy amable en la que le decia: Excelencia, Deseo agradecer las sinceras expresiones de amitad hacia España y hacia mi persona contenidas en el mensaje que me entregó, en su reciente visita a Madrid, el Vicepresidente de la República de Guinea Ecuatorial. Lamento que las ineludibles obligaciones de vuestro alto cargo, y vuestro celo en velar por el bienestar de vuestro pueblo, os hayan impedido desplazaros a esta capital. Sin embargo, aun siendo vuestra persona irremplazable, vuestros representantes han cumplido con exactitud y gran dignidad vuesira voluniad y me han hecho llegar la profunda y sincera amistad de la nación guineana, a la vez que, con toda franqueza que debe reinar entre pueblos hermanos, me han explicado la naturaleza y alcance de sus problemas actuales.

El Gobierno español, tened seguridad, señor Presidente, no dejará de ayndar a la nación guineana en esta elapa de la construcción de sits instituciones, sobre todo de tipo financiero $y$ de personal administrativo. Ha estado siempre claro desde el final de la Conferencia Constitucional, que ambos paises ven el futuro desde la perspectiva de la más absoluta independencia y el más estricto cumplimiento del principio de la no injerencia en los asunlos internos de cada uno de ellos; pero, también de la cooperación en el campo de la economia, de la enseñanza, de la promoción social y de la asistencia administrativa. 
Tened la seguridad, señor Presidente, que las peticiones de ayuda, fundadas y bien esiudiadas, encontrarán en mi Gobierno y en mi mismo la mejor disposición. Por la experiencia de los años de gobierno que la Providencia ha querido asignarme que un pais aumenta su crédito y prestigio internacional, más que por grandiosos planes de desarrollo, mediante la voluntad de su pueblo y Gobierno de ayudarse así mismos con una decidida voluntad de trabajo, de servicio austero, de sereno realismo. España está dispuesta a ayudar en estos temas con la aportación de su cooperación administrativa y técnica.

El sistema de cooperación entre los dos paises encontrará su debido marco en la celebración de una serie de acuerdos. Me parece muy necesario que sin excesiva dilación se preparen las posiciones negociadoras por ambas partes y se proceda a negociar los Convenios en el orden que nuestros Ministros de Asuntos Exteriores consideren más conveniente.

Sin duda, antes de dichas negociaciones será necesario atender a situaciones que no pueden esperar. Entre ellas, a la prórroga del presupuesto propio para el primer trimestre de 1969. El Ministerio de Hacienda español está dispuesio a enviar una misión a Guinea Ecuatorial para encontrar una rápida solución a estos problemas.

Como V.E. sabe, el Gobierno español se ha ofrecido, si el Gobierno guineano lo desea, a prestar su cooperación económica para el desarrollo de la economia guineana Es mi esperanza que Guinea y España den un ejemplo al mundo de relaciones armónicas, en el periodo que sigue a la descolonización, y de cooperación en el desarrollo económico y social del pueblo hasta hace poco tutelado. Reciba, etc. Francisco Franco. ${ }^{9}$ La carta está fechada en El Pardo el 24 de Enero de 1969. Como vemos, Franco, o mejor, su ministro de Asuntos Exteriores, Señor Castiella, no hace a Macias ninguna referencia sobre los discursos que éste estaba pronunciando. España, pese a todo, estaba dispuesta a cumplir sus compromisos con Guinea y, muy especialmente, con el pueblo guineano que durante años había ostentado la nacionalidad española.

Pero la verborrea del Presidente sí fue contestada por el embajador de España en Santa Isabel, quien hizo saber a Macias que su Gobierno estaba muy preocupado por la situación por la que estaban atravesando la mayoría de los españoles residentes en Guinea. Macias le contestó que: "mi Gobierno no ejerce el control de Río Muni". Y ante la sorpresa del propio embajador le pidió que la Guardia Civil debía permanecer en Guinea como único medio de mantener el orden público en su pais. Y así fue siempre Macias. Cuando tomaba la palabra para dirigirse al pueblo guineano era incapaz de contenerse y salía de sus labios gran cantidad de disparates que luego, y más sosegadamente, comprendía que las amenazas que pronunciaba contra España eran irrealizables, por el momento. De ahí que solicitase al embajador de España la conveniencia de que la Guardia Civil permaneciese en Guinea, al menos hasta que él estuviera bien asentado en el poder.

Antes de la independencia de Guinea, el Gobierno español habia autorizado al Comité Internacional de la Cruz Roja, con fecha 3 de Septiembre de 1968, para realizar vuelos de

9 Archivo del Ministerio de Asuntos Exteriores. Guinea Ecuatorial. Palacio de El Pardo 24 de Enero de 1969. 
ayuda humanitaria desde Bata a Biafra ${ }^{10}$. Al acceder Guinea a su soberanía, esa potestad había pasado a depender del Gobierno de Guinea, que los suspendió con fecha 14 de Enero de 1969, alegando que estos aviones transportaban también combustibles. El Comité Internacional de la Cruz Roja argumentó que ese combustible era necesario para que las ambulancias de Biafra pudieran funcionar. La complicada cuestión de la ayuda a Biafra iba a provocar muchas tensiones con el Gobierno de Guinea, por lo que se hizo necesaria una reunión del Ministro de Asuntos Exteriores de Guinea con el Secretario General de las Naciones Unidad y con un Representante del Gobierno norteamericano. Con motivo de estas entrevistas el Gobierno guineano autorizó la reanudación de los vuelos el 12 de Febrero, aunque solo por un período de un mes, durante el cual la Cruz Roja Internacional debía evacuar todos los depósitos que tuviera en Guinea. Macias solo reconocía al Gobierno de Nigeria, aunque no le preocupaba en absoluto la situación de guerra civil que se vivia en aquella zona. Sí le preocupaba el hecho de que hubieran tantos extranjeros viviendo en Bata $\mathrm{y}$, sobre todo, el hecho de no tener el control de los numerosos vuelos que se realizaban desde su país.

Como ya hemos dicho, el 13 de Febrero el Presidente Macias se encontraba en la zona continental de Guinea. En todos los discursos pronunciados volvió a utilizar un lenguaje áspero y racista antiblanco; todos estos discursos fueron creando en el ánimo de los europeos residentes en Guinea un sentimiento de preocupación.

Mientras, y como asi se contemplaba en los Tratados de Viena, la bandera de España ondeaba en la Cancilleria del Consulado, en la residencia del cónsul y en el acuartelamiento de la Guardia Civil. Estas fuerzas habían permanecido en Guinea por haberlo así acordado los Gobiernos de España y Guinea en los acuerdos firmados el mismo día de la independencia. El 16 de febrero de 1969 el Jefe de la Casa Militar de Macias conminó al cónsul de España para que retirase la bandera de la Cancilleria del Consulado. El Cónsul le contestó que no tenia ningún inconveniente en arriar la bandera siempre que dicha orden se hiciese por el conducto diplomático habitual. Le recordó al militar, aunque éste no entendiera nada de lo que le estaba hablando, que el uso de la bandera era un derecho consagrado en el Derecho internacional, y más concretamente, por el Convenio de Viena de 1963. El Cónsul general dirigió una Nota verbal al Presidente Macias, que se encontraba en Bata, en la que le informaba que el Consulado se atendría a lo que dispusiese el Gobierno de Guinea siempre que se hiciese por escrito. Pero Macias no hizo ningún caso a estas sugerencias y, el 26 de Febrero un destacamento de la guardia territorial, al mando de un comandante, violó la soberanía del edificio del Consulado de España en bata, y arrió, con violencia la bandera. El Cónsul General protestó enérgicamente, y a las pocas horas recibió una comunicación de Macias en la que se le declaraba persona non grata, y su inmediata expulsión del país.

Ante esta situación, el Embajador de España se trasladó inmediatamente al continente para hablar con Macias. Éste perdió, quizá por primera vez, el control de sí mismo y ame-

10 Biafra. República secesionista del sur de Nigeria, pais del que se queria independizar. La guerra duró treinta meses y el Gobierno de Guinea se alineó con las tesis de Nigeria en contra de la separación de Biafra. 
nazó al Embajador con declararle a él mismo persona non grala, cosa que, finalmente, llevó a efecto. En este ambiente enrarecido los residentes españoles en Río Muni comenzaron a ponerse verdaderamente nerviosos y fueron concentrándose en Bata, solicitando, por primera vez, ser evacuados. El Gobierno español ordenó inmediatamente a las fuerzas de la Guardia Civil que permaneciesen acuarteladas y que no saliesen, en absoluto, de sus bases, con el fin de evitar cualquier enfrentamiento con las fuerzas de la Guardia Territorial evitando, así, las excusas que el Presidente debía estar buscando. El Gobierno español se equivocó. No hubiese sido necesario intervenir pues hubiese bastado recordarle a Macias que si algún ciudadano español resultaba malherido, la Guardia Civil intervendría. Con esto hubiese acabado todo.

El 28 de Febrero el Presidente Macias envia el siguiente telegrama a Franco. "De Presidente de la República de Guinea Ecuatorial a Su Excelencia Francisco Franco Bahamonde, jefe del Estado español. Por haber sido declaradas personas no gratas el actual Embajador y el Cónsul españoles acreditados en Guinea Ecuatorial con esia fecha dispongo su expulsión debiendo el Gobierno español designar sustitutos lo antes posible. Asi mismo reitero a Vuecencia la evacuación inmediata de las fuerzas armadas españolas estacionadas en el territorio de la República de Guinea Ecuatorial. Alta consideración. Francisco Macias Nguema."

El dia antes Macias había enviado un telegrama al Secretario General de las Naciones Unidas: "Tan solo por haberse invitado a la representación diplomática españolas acreditada en esta República redujese el número de banderas igual que demás Estados acreditados, el Embajador español que además retiene unilateralmente varios edificios públicos ha realizado una serie de actos provocativos contra la soberania de Guinea Ecuatorial. Los actos cometidos por el Embajador son los siguientes: movilización general fuerzas españolas; ocupación dichas fuerzas aeropuerto de Santa Isabel; ocupación telégrafos y Correos; fuerzas españolas armadas pairullan por las capitales; traslado del buque español de Santa Isabel al puerto de Bata (esto se era cierto); reparto de armas a la población española residente en la República; sustitución violenta de la fuerza nacional guineana por fuerzas españolas. Por todo ello, el Gobierno de la República de Guinea Ecuatorial denuncia ante el Secretario General de las Naciones Unidas y todo el mundo los hechos de los que es responsable el Gobierno español. El Gobierno de la República de Guinea Ecuatorial solicita la presencia de fuerza de paz de esa Organización y ponga estos hechos en conocimiento del Consejo de Seguridad. Alta consideración. Francisco Macias Nguema. Presidente de la República de Guinea Ecuatorial. ${ }^{12}$

Por otra parte el mismo día 28 Macias había enviado un segundo telegrama a Franco en los siguientes términos, en el que hacia referencia a otro enviado por Franco: Pongo en conocimiento Jefe Estado español numerosos actos de violación soberania este país con violación personas y bienes de guineanos por fuerzas Guardia Civil españolas estacionadas

11 SIN/96. Bata 742816,44 de 28 de Febrero de 1969. Ministerio de Asuntos Exteriores. Madrid.

12 Ministerio de Asuntos Exteriores. Madrid. Archivo de Guinea Ecuatorial. 
esta República. Este Gobierno ha actuado siempre sobre la base del respeto de todas las personas sea cual fuese su color, su raza, su condición social o credo. Por ello, jamás ha sido permitida medida alguna en sentido contrario. Por ello está consternado ante tales violaciones realizadas por la Guardia Civil contra la independencia que a este pais ha concedido la misma España y su Caudillo. Repito a VE contenido mi telegrama anterior que tan solo se permitió al Cónsul de España en Bata mantuviese una bandera en edificio destinado a Consulado España Bata. Solo por este hecho Embajador español ha ordenado movilización fuerzas; corte carburante; fuerzas Guardia Civil ha ocupado aeropuerto; Guardia Civil ha disparado sobre indefensa población nativa civil: Por ello solicito urgente sustitución Embajador y Cónsul españoles destinados en Guinea por otros de distinta mentalidad. Debo informar a VE constantes instigaciones por Embajador y Cónsul españoles a población española para que abandone este pais en contra politica Gobierno español y deseo de los propios españoles y contra esfuerzos Gobierno Guinea. Por ello, insisto a VE disponga urgente e inmediata evacuación fuerzas Guardia Civil española por otras hasta tanto mi Gobierno negocie sustitución por otra sin mentalidad colonial. Siempre con mi más alta consideración. Francisco Macias Nguema Presidente de la República de Guinea Ecuatorial. ${ }^{13}$

De estos tres telegramas podemos sacra dos conclusiones inmediatas. Por un lado la enrome capacidad de Macias Nguema para tergiversas los hechos e incluso para creerse sus propias mentiras. Y por otro lado, su enorme preocupación por la presencia en Guinea de la Guardia Civil española. Macias no quería tener testigos de todos los atropellos que estaba cometiendo contra la propia población guineana. Las cárceles estaban llenas y los guineanos estaban conociendo ya quien era su Presidente. Por todo ello le estorbaba la Guardia Civil que, por otra parte, era el único amparo de la población guineana. Sabemos que Macias era un paranoico cruel. Había sido funcionario de la administración española, en un puesto de ordenanza, es cierto, desde el cual fue escalando puestos hasta llegar a ser alcalde de Mongomo, su pueblo. ${ }^{14}$ Poco a poco fue escalando puestos en la administración española y en 1961 formó parte de la delegación de la Administración guineana que acudió a Madrid con motivo del 25 aniversario de la toma del poder por Franco. Es en esta fecha cuando se une, aunque por poco tiempo, al IPGE's y despues se afilió al MUNGE ${ }^{16}$. Macias nunca tuvo problemas con las autoridades españolas como ocurrió con otros líderes políticos que tuvieron, incluso, que exiliarse. En 1964 se convirtió en diputado de la Asamblea General y poco

13 Ministerio de Asuntos Exteriores. Madrid. Archivo de Guinea Ecuatorial.

14 Mongomo.- Situada en el centro-este de Río Muni, cerca de la frontera con Gabón. Durante la época de la provincialización gozó de un auge económico importante por su condición de ciudad fronteriza. Durante todo el mandato de Macias y de su sucesor, Obiang, ha sido la patria de donde han salido todos los ministros y militares del Gobierno de Guinea, es lo que se conoce como el clan de Mongomo.

15 IPGE.- Idea Popular de Guinea Ecuatorial. Movimiento de los más radicalizados de Guinea pues no querian solo la independencia sino que querian, además, formar una federación con Camenún. Apoyó a Macias en las presidenciales de lo que solo obtuvo una cartera ministerial, la de salud Pŕblica.

16 MUNGE.- Movimiento de Unión Nacional de Guinea Ecuatorial. La uparición de este partido en la escena pública guineana fue propiciada por el Gobierno español. bajo la presidencia de Ondó Edú. Durante la autonomía este partido perdió su razón de ser y además Ondó Edú fue nombrado Jefe del Gobierno autónomo. 
después en vicepresidente del Consejo del Gobierno autónomo. Macias participó en las dos sesiones de la Conferencia Constitucional de Madrid y fue en esta época cuando entro en contacto con García Trevijano. Este personaje merece algo más que una Nota a pié de página. Nación en Valencia aunque era originario de Granada. Profesor de Universidad, abogado en ejercicio y notario. Durante la Conferencia Constitucional ofreció sus servicios de asesoramiento al grupo próximo a Macias, en contra de los propios intereses de Carrero Blanco que apoyaba decididamente a Ondó Edú, Presidente del Gobierno autónomo. Pagó todos los gastos de la comitiva de Macias, durante su estancia en Madrid y habría pagado, incluso un viaje de Macias a Nueva York para que Macias presentara en Naciones Unidas su proyecto de independencia para Guinea Ecuatorial. Cuando Macias se convirtió en Presidente de Guinea, Trevijano realizó su primer viaje a al país donde, además de ser nombrado Caballero de la Orden de la Independencia consiguió importantes concesiones forestales. En 1972, las autoridades españolas le retiraron su pasaporte y le prohibieron la entrada en España. Más tarde y con ocasión de las primeras elecciones democráticas españolas fue el dirigente de Coordinación democrática independiente, próxima al partido comunista. En 1976 fue encarcelado y siempre protestó diciendo que había sido la víctima de una campaña denigratoria contra su persona. Fue el autor del discurso la proclamación de la independencia pronunciado por Macias en Octubre de 1968. Este siniestro personaje fue durante muchos años el principal consejero de Macias en contra de los intereses de España en Guinea Ecuatorial. Pero, llegados a este punto, creo que el Gobierno español se equivocó al ceder a las presiones de Macias para que la Guardia Civil fuese evacuada de Guinea Ecuatorial. La Historia no se puede hacer de atrás hacia delante, pero sí era evidente que en otros países que también acaban de acceder a su independencia pronto habian empezado los problemas y que éstos había sido de orden menor porque en aquellos paises habían permanecido las tropas coloniales. Estoy convencido que si el Gobierno español hubiese mostrado firmeza, sin necesidad de emplear la fuerza, frente a los desmanes de Macias, éste no se hubiese convertido en el ser sanguinario y despreciable que llegó a ser. España tendría que haber hecho valer los derechos que le concedia los tratados firmados con la República de Guinea y se hubiesen podido evitar las violencias y atropellos del régimen de Macias.

Atanasio Ndongo, ministro de Asuntos Exteriores de Guinea aparecía como el único interlocutor válido de España y a él dirige el 4 de Marzo una carta el ministro de Asuntos Exteriores español: "Le agradezco sus esfuerzos por solucionar la situación actual que, como bien sabe, España en modo alguno ha provocado. Estamos seguros de que el pueblo guineano apreciará nuestro afán por salvar hasta donde sea posible el clima de amistad en las relaciones con España.

Creo sin embargo necesario clarificar la posición del Gobierno español y reiterarle nuestros firmes propósitos que desde el primer momento hemos expuesto en distintos mensajes a S.E. el Presidente de la República de Guinea propósitos que aparecen también reflejados en nuestros mensajes al Secretario General de las Naciones Unidas y al Secretario General de la OUA.

V.E. es testigo de excepción de que España nunca estuvo interesada en mantener de Guinea fuerzas de orden público o de cualquier otro tipo. Si en los Acuerdos transitorios se preveía la presencia de una fuerza simbólica era por haber mostrado interés en ello el 
Gobierno de Guinea. En las condiciones actuales el Gobierno español ha decidido retirar definitivamente sus fuerzas militares de todo orden, las cuales habrán de salir de Guinea con el último de los españoles que libremente deseen abandonar el territorio.

Creeemos que un plazo de quince dias puede ser suficiente si encontramos en ese Gobierno la esperada cooperación. Entendemos ha de autorizarse la salida no solo de los familiares sino de todos los españoles que voluntariamente lo soliciten, incluyendo a los funcionarios. Ello es de estricto derecho porque lodavia no están ligados al Gobierno guineano por contrato alguno y por tanto pueden solicitar su traslado a España.

A este respecto quiero señalar a V.E. que el Gobierno español no pretende con tal postura inducir a un éxodo en masa a la población española, población que contribuia a la politica de cooperación y desarrollo de Guinea que siempre habiamos propugnado, pero lo que el Gobierno español no puede aceptar es que se impida la salida del territorio de aquellos españoles que se encuentran aterrorizados y a los que las normas internacionales les otorgan su completo derecho a reintegrarse a su Patria.

Para llevar a cabo este plan seria necesario que el Gobierno guineano permitiera, de acuerdo con las normas de derecho internacional, que nuestra Representación diplomática y consular en Guinea pudiera ejercer libremente sus funciones, trasladándose a todos los lugares del territorio para entrar en contacto con la población española y que esta misma Representación tuviera libertad de comunicaciones' entre la Embajada y sus Consulados y entre la Embajada y España.

Pasado el plazo antes indicado y si se hubieran cumplido estos requisitos, las fuerzas españolas abandonarian Guinea Ecuatorial, no pareciendo necesario por lo tanto la firma del Acuerdo militar que me proponia V.E. en el telegrama que me ha dirigido. Saludale, Fernando Maria Castiella, Ministro de Asuntos Exieriores de España. ${ }^{17}$

Ndongo Miyone había sido, desde su juventud, un luchador por la libertad e independencia de Guinea Ecuatorial, lo que le valió numerosos arrestos y finalmente el exilio a Gabón, donde fue muy bien recibido por el Presidente de aquella República, León Mbá casándose con una de sus hijas. En 1966 Ndongo Miyone regresó a Guinea formando parte del grupo del Monalige, y participó en la Conferencia Constitucional de Madrid. Se presentó a las elecciones a la Presidencia de Guinea Ecuatorial y fue el tercer candidato más votado. En la segunda vuelta de éstas elecciones apoyó a Macias Nguema en detrimento del otro candidato Ondó Edú que, con su apoyo hubiera sido elegido Presidente en lugar de Macias. El nuevo Presidente de la República premió a Ndongo Miyone con la cartera de Asuntos Exteriores donde desarrolló una brillante gestión pese a lo problemático que se estaba convirtiendo pertenecer al Gobierno de Macias Nguema. El 5 de Marzo de 1969, Ndongo Miyone habria sido acusado de estar preparando un golpe de Estado para desbancar a Macias lo que nunca ha podido ser probado. Lo cierto es que ese día Ndongo Miyone acudió al Palacio Presidencial de Bata para asistir a un Consejo de Ministros que había convo-

17 Dirección General de Árica y Próximo Oriente. Telegrama de 4 de Marzo de 1969. Ministerio de Asuntos Exteriores. Madrid. 
cado el Presidente Macias. En dicha reunión, Macias habría acusado a Ndongo Miyone de ser más partidario de las tesis españolas durante la crisis que de las suyas propias. Se debió producir una violenta discusión entre ambos mandatarios como consecuencia de la cual los partidarios de Macias defenestraron a Ndongo Miyone. La muerte de Ndongo fue seguida por una tremenda pura, con los asesinatos de Ondó Edú, Gori Molubela, Mitogo Etosa, Itoha Iyanga 0 otros muchos más. La veda se había levantado.

De nuevo tengo que ser muy crítico con la posición que el Gobierno español tuvo a raíz de todos estos acontecimientos. Se había permitido la crítica feroz de Macias contra la presencia española en Guinea, en la creencia que sería pasajera; Se había protestado con muy baja intensidad al allanamiento del Consulado General de España en Bata. Se silenciaron todos los atropellos cometidos por Macias contra las personas e intereses de los españoles en Guinea y, finalmente, habia aceptado la salida de la Guardia Civil de Guinea Ecuatorial, eso sí, cuando hubiesen abandonado Guinea todos los españoles. Por todo ello, la política seguida por el Gobierno español en Guinea Ecuatorial desde el mismo día de la independencia fue de dejación total. España tenía todo a su favor. Tenía el consentimiento implícito de la mayoría de la población guineana; Tenía el derecho a que la Guardia Civil permaneciera en Guinea, en virtud de los Acuerdos Transitorios. Tenía, y esto es lo más importante, el deber a salvaguardar la integridad de la población de Guinea, aún en contra de su propio presidente. Pero España, en una actitud enana, abandonó a Guinea Ecuatorial a su suerte, y lo que es peor, condenó a los guineanos a un fuluro incierto cuyas consecuencias aún se están sufriendo. No acabo de entender el complejo de inferioridad que España mantuvo en Guinea pues, todavía, se insistía en una Nota Informativa de 6 de Marzo "en que España no ha participado ni tiene intención de intervenir en los asuntos guineanos y mucho menos cuando se trata de una lucha por el poder."18

A los pocos días del "asesinato" de Ndongo Miyone, el Encargado de Negocios de la Embajada de España en Santa Isabel, señor Pan de Soraluce, que acababa de incorporarse a su misión mantuvo una entrevista con el Presidente Macias quien le manifestó su certeza de que la Guardia Civil no había estado involucrada en el Golpe de Estado de Ndongo Miyone. Parecía una actitud conciliatoria pero a los pocos días volvía a reiterar su petición de cascos azules al Secretario General de las Naciones Unidas. Macias no iba a estar tranquilo hasta que la Guardia Civil abandonase Guinea.

A estas alturas de los acontecimientos, España hacía tiempo que habia tomado la decisión de que la Guardia Civil abandonase Guinea, pero ello debía ir seguido de la salida de todos aquellos funcionarios españoles al servicio de Guinea, que quisiesen abandonar Guinea, a lo que se oponía rotundamente el Gobierno guineano. Mientras tanto, la situación continuaba deteriorándose. El Gobierno guineano sabía lo problemático que podía resultar para su economía la salida masiva de todos los funcionarios españoles y por ello se oponía con la fuerza a la misma. Esto motivo, y no otra cosa, que la corbeta "Descubierta" que se

18 Nota Informativa sin numero de seis de marzo de 1969. Dirección General de África y Medio Oriente. Ministerio de Asuntos Exteriores. Madrid. 1969. 
encontraba en el puerto de Santa Isabel, en virtud de los acuerdos transitorios, se trasladase a Bata para acompañar a los barcos que hacían el servicio regular entre bata y Santa Isabel, el "Ciudad de Toledo" y el "Ciudad de Pamplona". Se trataba de proteger el embarque de todos aquellos españoles, funcionarios o no, que deseaban abandonar Guinea Ecuatorial. El Gobierno guineano, no teniendo medios para impedir la salida del "Descubierta", reaccionó aislando por completo la Embajada de España en Santa Isabel. Las comunicaciones telefónicas y telegráficas fueron intervenidas, se prohibió el relevo de los guardias civiles que prestaban servicio en la propia Embajada que, sin embargo, está rodeada por tropas de la guardia territorial guineana. Y además, el Gobierno guineano seguía impidiendo la salida de los funcionarios españoles. Sólo a partir del seis de Marzo iba a permitir la salida de las mujeres y de los niños. Lo cierto que esta actitud del Gobierno guineano atentaba contra el Derecho internacional puesto que la vinculación que estos funcionarios no estaba ligada por ningủn contrato con el Gobierno guineano, sino que dicha vinculación era con el Gobierno español, que los había puesto al servicio del guineano.

En la mañana del lunes 10 de Marzo el Encargado de Negocios de la Embajada de España en Santa Isabel tuvo noticias de que el Vicepresidente de la República señor Bossio estaba manteniendo una reunión en la Cámara de Comercio de Bata con los españoles a los que exhortó a que no abandonasen Guinea, dándoles todo tipo de seguridades de que sus personas y bienes serían respetados por el Gobierno de Guinea Ecuatorial. Sin embargo, aún por esta fecha, se seguía impidiendo el embarque en el "Ciudad de Bilbao" a aquellos españoles que deseaban abandonar Guinea. Para aclarar la situación, el señor Pan de Soraluce, acompañado por los señores Moráll y Arístegui se trasladan a Bata, en cuyo aeropuerto se cruzan los algunos periodistas extranjeros, y uno de ellos, el señor Tripini les manifiesta estar horrorizado por la violencia desencadenada por Macias y sus juventudes. ${ }^{19}$ Los tres diplomáticos españoles tuvieron, ante las amenazas de las "juventudes" que refugiarse en el acuartelarniento de la Guardia Civil, de donde no pudieron salir hasta el dia siguiente en el que el Encargado de Negocios se decidió a tomar otra vez la iniciativa y se dirigió al Palacio Presidencial para obligar a Macias a que le recibiera. Sufrieron multitud de controles $y$, finalmente, fueron rescatados por el Representante de Naciones Unidades ante el Gobierno de Macias, señor Tamayo, quien logró una entrevista del señor Pan de Soraluce con el Presidente Macias. Al llegar al Palacio, la Delegación española, volvió a sufrir toda suerte de cacheos y violencias y al cabo de un par de horas se les permitió subir al piso donde se encontraba Macias. Se realizó una entrevista tres, el señor Tamayo, el señor Pan de Soraluce y el Presidente Macias, quien consintió en permanecer a solas con ellos sin su guardia personal. Macias insistió en su petición de cascos azules a lo que el Representante de Naciones Unidas argumentó que para ello era necesario la convocatoria previa del Consejo de Seguridad a lo que se oponian incluso los miembros africanos no permanentes de dicho

19 Las juventudes en inarcha con Macias. Movimiento perteneciente al PUNT, partido único nacional de trabajadores fundado por Macias. Estaba compuesto por jóvenes de ambos sexos. Iban armados e uniformados y actuaron durante todo el régimen de Macias con total impunidad. 
Consejo. El señor Tamayo le dijo a Macias que una nueva crisis en una zona tan peligrosa como la del Golfo de Biafra podría tener repercusiones internacionales muy negativas para Guinea. En este punto de la entrevista y, ante la fortaleza encontrada por Macias en el señor Tamayo, cambió radicalmente de actitud. Y dijo estar dispuesto de forma inmediata a la salida inmediata de todos los españoles que deseasen abandonar Guinea, a garantizar la seguridad personal de aquellos que deseaban permanecer en Guinea, estar dispuesto a manifestar esto por escrito en un documento dirigido al Secretario General de las Naciones Unidas y, por último, a negociar todo esto en plan amistoso con España. El tono de la entrevista fue amistoso sin que faltasen algunos momentos de exaltación por parte de Macias pero, en cualquier caso, se habia logrado reconducir una situación que estaba en punto muerto. El Encargado de Negocios de España al advertir la buena disposición de Macias le pidió que, en prueba de buena voluntad hacia España debian cesar sus discursos en los que exaltaba a la población guineana contra España. Macias asintió. El Presidente preguntó al señor Pan de Soraluce si todavia se estaba a tiempo de impedir el éxodo de los españoles a lo que éste replicó que creía que sí pero que era necesario que él personalmente visitase a todos los españoles residentes en la zona continental de Guinea para preguntarles personalmente cual era su decisión. Para ello era necesario que Macias le permitiese moverse por el pais con toda libertad y con escolta de la Guardia territorial guineana para impedir los desmanes de las "juventudes en marcha con Macias". El Presidente consintió, y alegó que en esos mementos había logrado disciplinar a dichas juventudes que, en algunos momentos, se les habían escapado de su propio control pero que, a partir de ahora la situación estaba bajo control. Por otra parte, Macias se desdijo de su primera aseveración y admitió ante el Representante del Secretario general de Naciones Unidas que España no habia tenido nada que ver con el reciente intento de golpe de Estado. Fue en este momento cuando Macias cambió nuevamente de actitud y entró en el fondo de la cuestión. Afirmó estar muy enfadado con el Gobierno español porque no le había mandado toda la ayuda económica que le había solicitado lo que estaba llevando a su régimen a la ruina y que si España se mantenía en esta actitud estaba dispuesto a solicitar ayuda a Estados Unidos o a algún otro país. El Representante de España le dijo que estaba todo preparado pero que la crisis había impedido que ambos paises se reuniesen para preparar unos acuerdos comerciales. "Tráigame usted esos acuerdos, los estudiamos y empezamos de nuevo", dijo Macias. El Presidente Macias prometió que no iba a proferir más discursos antiespañoles y que iba a presidir en los días siguientes una ceremonia en la que estaria el Representante de España y el de Naciones Unidas en la que explicaria a las Juventudes la nueva línea de actuacion..$^{20}$

Pero, pese a las seguridades que Macias había dado al Representantes de Naciones unidas volvió a romper su palabra el 21 de Marzo al reiterar a Franco su petición de que la Guardia Civil abandonase Guinea inmediatamente, aunque todavia no hubiesen salido de Guinea todos los españoles. Pero España todavía estaba dispuesta a más y el 21 de Marzo

20 Carta al Señor Ministro de Asuntos Exteriores dirigida por el Subdirector General de África Subsaharina Don Fernando Morán. Madrid, 10 de Marzo de 1969. 
de 1969, Franco envió un nuevo telegrama a Macias: ...mucho lamento que crisis sufrida por vuestro paies haya producido en los españoles ahi residentes impresión de falta de seguridad y de garantias en un ambiente de hostilidad fomentado por acusaciones gratuitas. sacrificio que representa evacuación para quienes ahi dedicaron su vida acusa la inseguridad en que se consideraron. La serenidad de las fuerzas españolas fiente al desorden y la inseguridad que ha reinado estos últimos dias en Guinea Ecuatorial, es una prueba de la inalterada actitud mantenida y constituye una valiosa contribución a la amistad de los pueblos guineano y español a cuyo servicio respondia la presencia en territorio guineano por mutuo acuerdo entre los dos Gobiernos. En este orden espero comprenderéis el que rechace con toda firmeza el que la presencia de la Guardia Civil en sus acuartelamientos pudiera ser motivo de provocación para el pueblo guineano. Nuestios informes cuya exactitud puede sufrir alteración debido a dificultades que encuentran nuestros representantes para ejercer normalmente su labor, señalan que quedan aún más de dos mil españoles en Santa Isabel y alrededor de un centenar en bata, de los cuales la mayoria desea reintegrarse a su Patria. Considero que el restablecimiento de la calma y el orden que me anuncia en su telegrama, alimentan la esperanza del Gobierno español para que el Gobierno de VE, y autoridades guineanas presten la colaboración para la salida de españoles lo deseen en el plazo más breve posible y entonces tendrá lugar la retirada de las tropas españolas en condiciones de seguridad, orden y honor merecen su leal cooperación a Guinea Ecuatorial y que son de esperar del Gobierno pueblo guineano. ${ }^{21}$

A los pocos días abandonaron Guinea los últimos españoles y con ellos las tropas de la Guardia civil. La crisis habia terminado. Ahora y a modo de conclusión quiero añadir que en Octubre de 1979 fui destinado al Consulado General de España en Bata. Habían pasado 10 años y los españoles, tras la caída violenta de Macias, aterrizábamos de nuevo en Guinea Ecuatorial. Los dos primeros años de mi estancia en Bata estuvieron jalonados de dificultades pero desde el Consulado, desde donde se dirigia la cooperación, era muy gratificante trabajar. Teníamos lo principal, la cooperación de las autoridades guineanas y sobre todo, el apoyo decidido del pueblo guineano, cansado de los atropellos del tigre de Mongomo, como se conocía a Macias. Pero, sin que apenas nos diéramos cuenta, a partir de 1981 la situación comenzó a cambiar. El nuevo Presidente, Obiang Nguema, sobrino carnal de Macias, volvió a las andadas y el Gobierno español, ahora con un régimen democrático, volvió a equivocarse haciendo una completa dejación de los derechos que le conferian los Acuerdos firmados con el nuevo Presidente de Guinea. Y el perdedor, como siempre, fue el pueblo guineano que nunca encontró, desde su independencia, en España el valedor que creía tener en la Madre Patria.

21 Telegrama claro num 328 de 22 de Marzo de 1969. Ministerio de Asuntos Exteriores. Madrid. 